
\title{
25 Research Soure \\ Fabrication of Gelatin Microspheres 1 Containing Ammonium Hydrogen Carbonate for the Tunable Release of Herbicide
}

He Liu

Dalian University of Technology

Zheng Zhang

Dalian University of Technology

jun yang ( $\sim$ junyang@dlut.edu.cn )

Dalian University of Technology https://orcid.org/0000-0002-4409-3099

Wanyu Zang

Dalian University of Technology

Qing Yang

Dalian University of Technology

\section{Research Article}

Keywords: gelatin microspheres, controlled release, temperature responsive, $\mathrm{NH} 4 \mathrm{HCO}$, herbicide

Posted Date: March 26th, 2021

DOI: https://doi.org/10.21203/rs.3.rs-326872/v1

License: (c) (i) This work is licensed under a Creative Commons Attribution 4.0 International License. Read Full License

Version of Record: A version of this preprint was published at Biotechnology Letters on July 18th, 2021. See the published version at https://doi.org/10.1007/s10529-021-03163-5. 


\section{Abstract}

The major challenge in utilizing pesticides lies in identifying the precise application that would improve the efficiency of these pesticides and reduce their environmental and health hazards at the same time. Such application requires the development of specific formulations that enable controlled, stimuliresponsive release of the pesticides. Gelatin is a relatively cheap material characterized by temperaturesensitivity and abundant amino acid groups, which makes it suitable for the storage and controlled release of pesticides. In this study, gelatin microspheres were prepared by emulsion and cross-linking, then they were loaded with 2,4-dichlorophenoxyacetic acid sodium (2,4-D Na) as a model herbicide. To achieve temperature-tunable release of 2,4-D Na from the microspheres, $\mathrm{NH} 4 \mathrm{HCO} 3$ was added to the formulations at different concentrations. The prepared formulations were characterized by SEM, FTIR, and size distribution analyses, and their drug loading capacities were determined. Based on bioassay experiments, the 2,4-D Na-NH4HCO3-loaded gelatin microspheres can effectively control the spread of dicotyledonous weeds. Therefore, the strategy proposed herein can be used to develop novel, effective herbicide formulations.

\section{Full-text}

Due to technical limitations, full-text HTML conversion of this manuscript could not be completed. However, the manuscript can be downloaded and accessed as a PDF.

\section{Tables}

Table 1 Average particle sizes of unloaded and 2,4-D Na-loaded gelatin microspheres.

\begin{tabular}{|lll|}
\hline & Gelatin microspheres & 2,4-D Na-loaded gelatin microspheres \\
\hline Particle size $(\mu \mathrm{m})$ & $253.61 \pm 11.27$ & $525.49 \pm 18.02$ \\
\hline
\end{tabular}

Table 2 Drug loading capacity and embedding ratio of microspheres with different concentrations of $\mathrm{NH} 4 \mathrm{HCO} 3$.

\begin{tabular}{|llll|}
\hline & $\begin{array}{l}2,4-\mathrm{D} \mathrm{Na} \text {-loaded } \\
\text { gelatin } \\
\text { microspheres }\end{array}$ & $\begin{array}{l}2,4-\mathrm{D} \mathrm{Na}-3 \% \mathrm{NH}_{4} \mathrm{HCO}_{3}- \\
\text { loaded gelatin } \\
\text { microspheres }\end{array}$ & $\begin{array}{l}2,4-\mathrm{D} \mathrm{Na}-6 \% \mathrm{NH}_{4} \mathrm{HCO}_{3}- \\
\text { loaded gelatin } \\
\text { microspheres }\end{array}$ \\
\hline $\begin{array}{l}\text { Drug loading } \\
\text { capacity } \\
\text { (mg/g) }\end{array}$ & $77.95 \pm 2.40$ & $43.96 \pm 1.25$ & $39.1 \pm 1.11$ \\
\hline $\begin{array}{l}\text { Embedding } \\
\text { ratio }(\%)\end{array}$ & $61.76 \pm 2.89$ & $37.88 \pm 1.12$ & $36.4 \pm 1.03$ \\
\hline
\end{tabular}


Table 3 Rootlength and weight on the 5th day.

\begin{tabular}{|lllll|}
\hline & Group 1 & Group 2 & Group 3 & Group 4 \\
\hline Root length $(\mathrm{cm})$ & $7.32 \pm 0.81$ & $3.81 \pm 0.34$ & $3.39 \pm 0.23$ & $3.23 \pm 0.25$ \\
\hline Weight $(\mathrm{g})$ & $0.29 \pm 0.0200$ & $0.16 \pm 0.0049$ & $0.09 \pm 0.0052$ & $0.06 \pm 0.0018$ \\
\hline
\end{tabular}

\section{Figures}

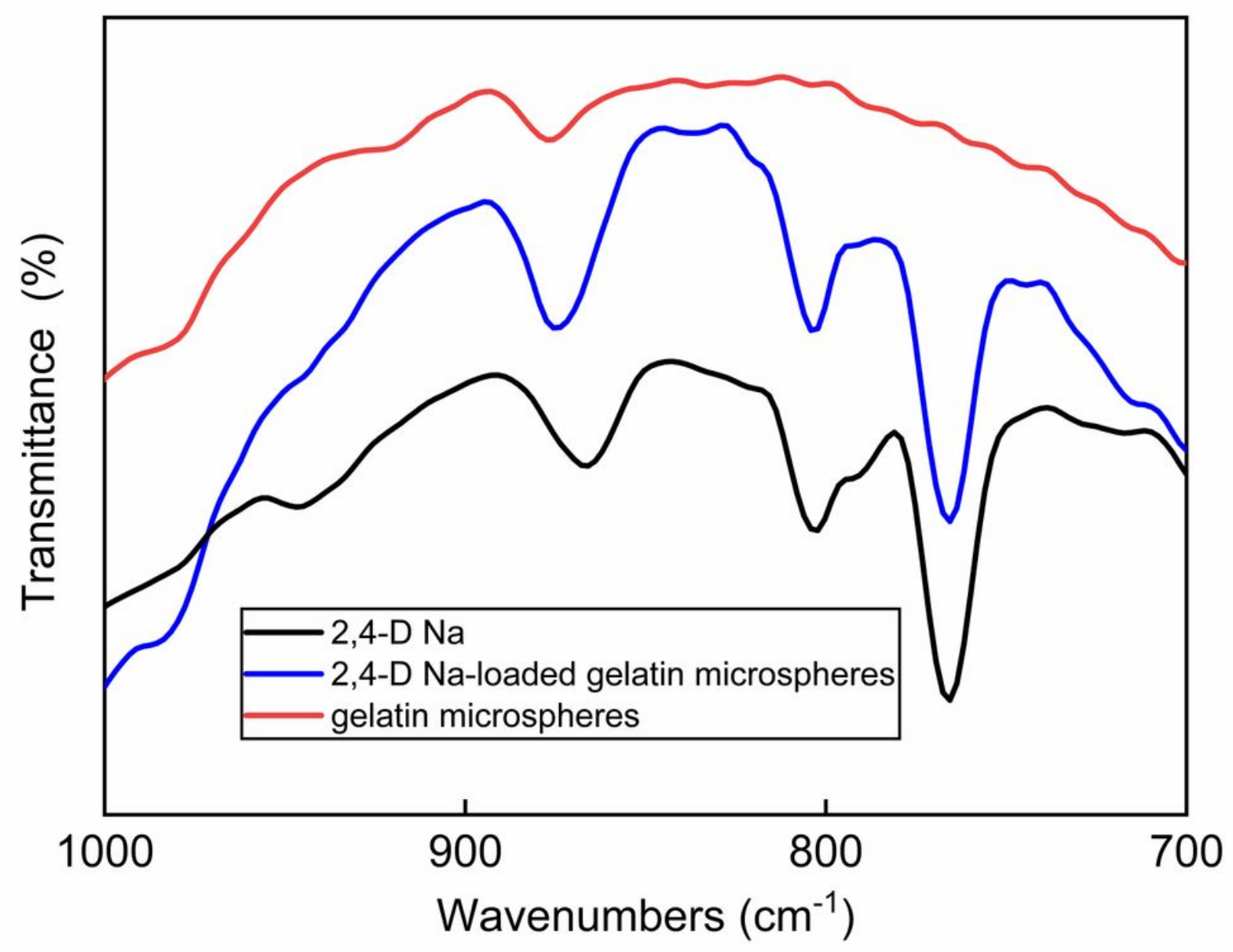

Figure 1

Infrared spectra of 2,4-D Na-loaded gelatin microspheres and unloaded gelatin microspheres in the range of $700-950 \mathrm{~cm}-1$ 

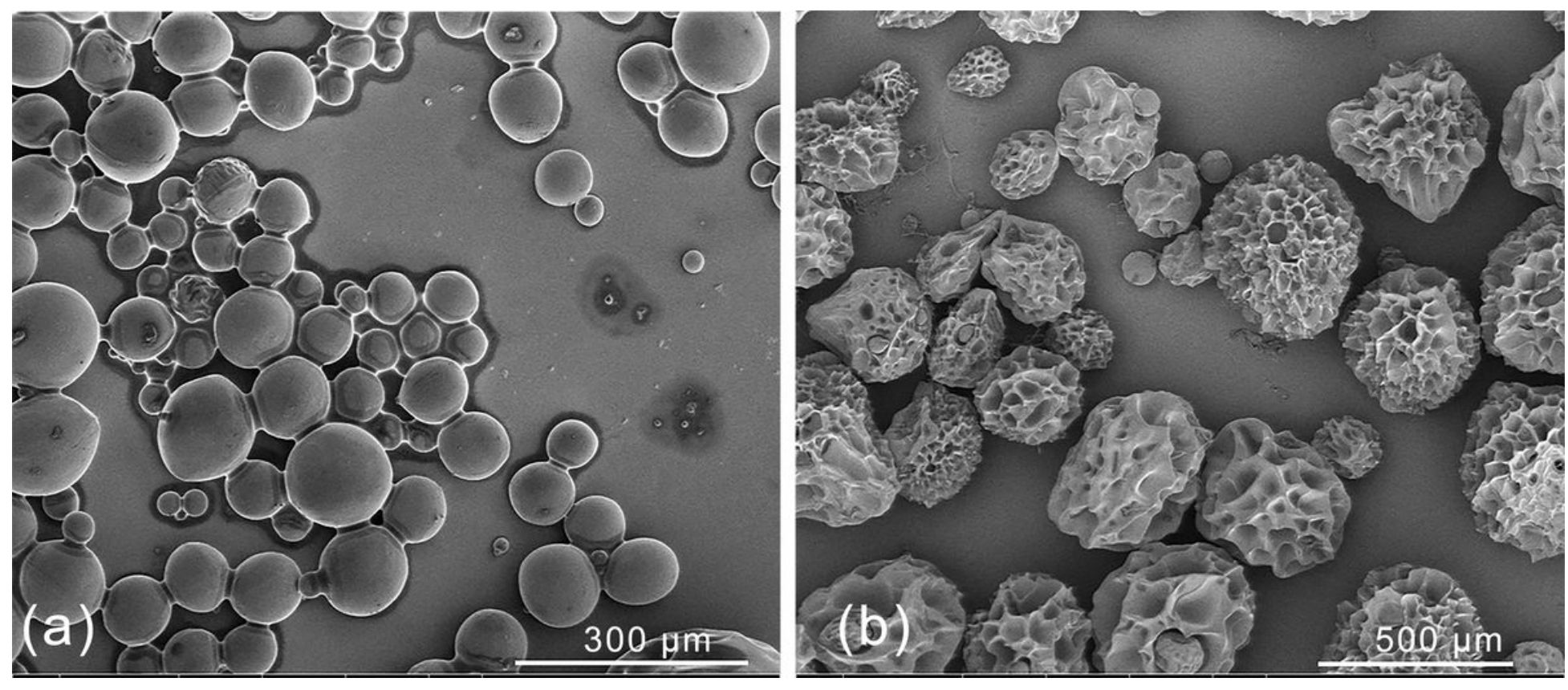

Figure 2

SEM images of (a) unloaded and (b) 2,4-D Na-loaded gelatin microspheres 

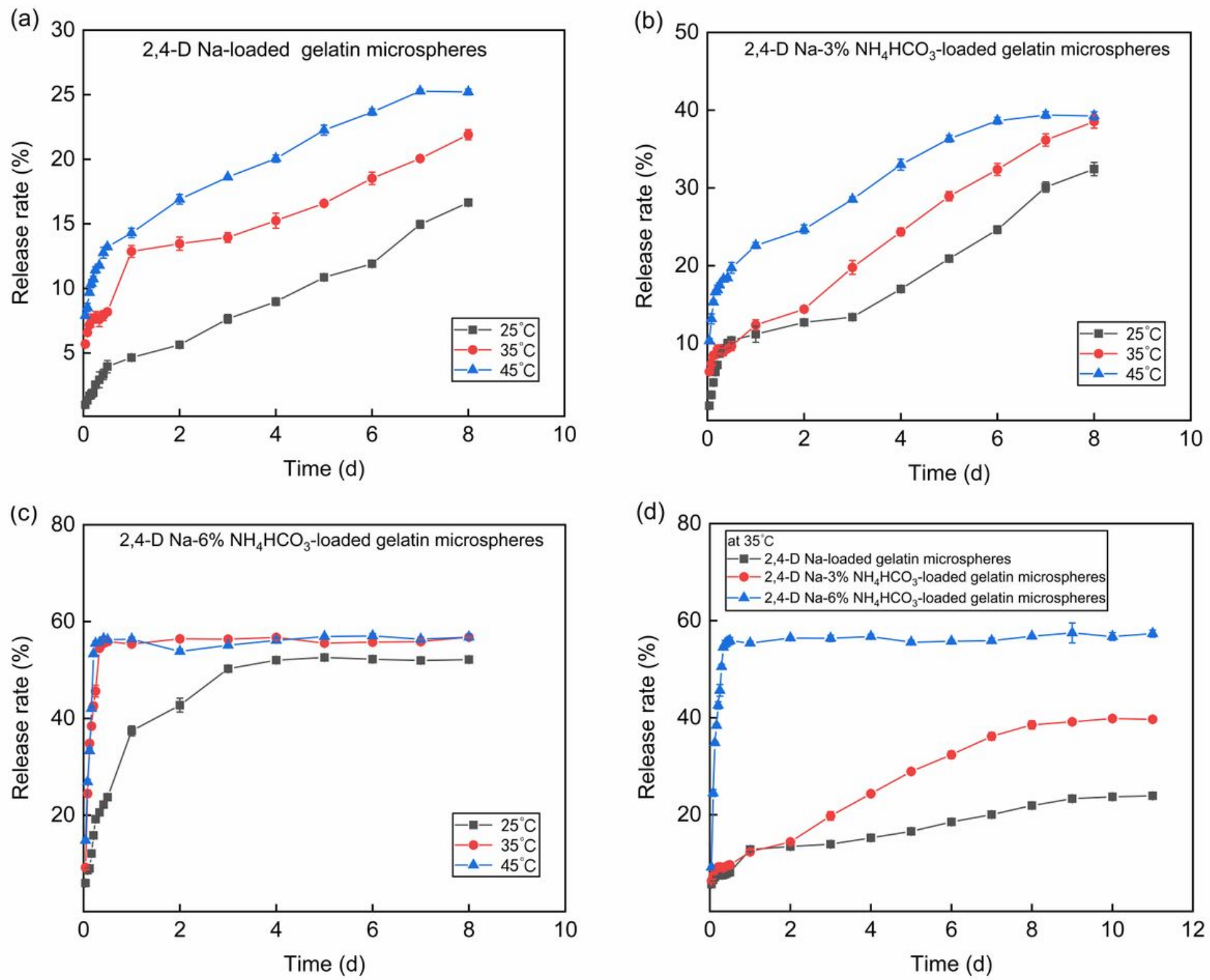

\section{Figure 3}

Sustained release curves of (a) 2,4-D Na-loaded gelatin microspheres (2-GM), (b) 2,4-D Na-3\% NH4HCO3loaded gelatin microspheres (2-3\% N-GM), and (c) 2,4-D Na-6\% NH4HCO3-loaded gelatin microspheres $(2-6 \% \mathrm{~N}-\mathrm{GM})$ at 25,35 , and $45^{\circ} \mathrm{C}$. (d) Release curves of different materials at $35^{\circ} \mathrm{C}$ 

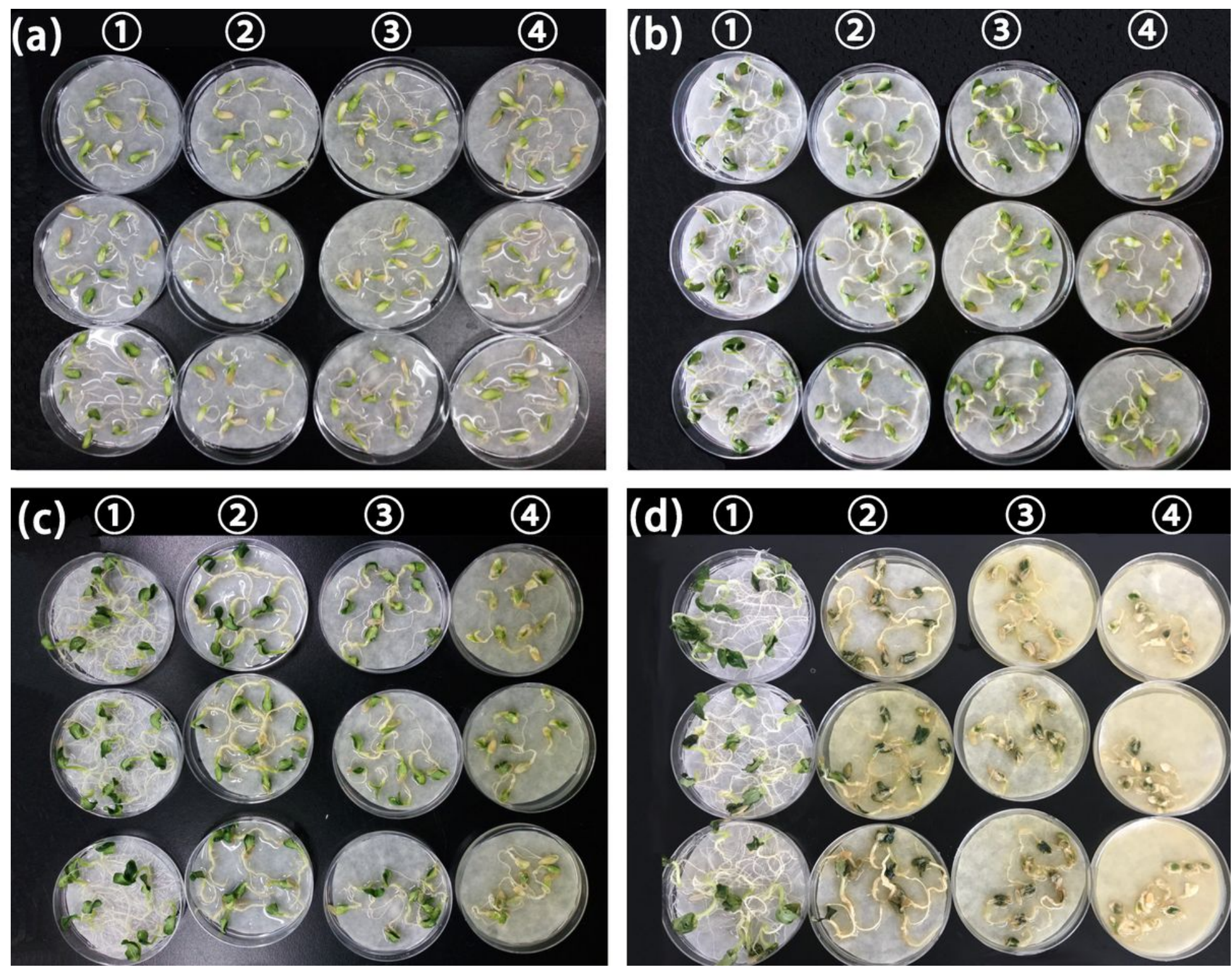

Figure 4

Inhibitoryeffects of the tested formulations on cucumber seedlings at $33^{\circ} \mathrm{C}$ after (a) 1 (b) 2 (c) 3 (d) 5 days of treatment.The numbers $₫$ - refer to different groups. Group 1 is blank control; Groups 2, 3 and 4 are treated with 2,4-D Na-, 2,4-D Na-3\% NH4HCO3 and 2,4-D Na-6\% NH4HCO3-loaded gelatin microspheres, respectively 